\title{
More than Maize, Bananas, and Coffee: The Inter- and Intraspecific Diversity of Edible Plants of the Huastec Mayan Landscape Mosaics in Mexico ${ }^{1}$
}

\author{
C. Heindorf ${ }^{*, 1}$, J. A. Reyes-Agüero ${ }^{2}$, J. Fortanelli-Martínez ${ }^{2}$, and \\ A. VAN 'T HOOFT $^{3}$
}

${ }^{1}$ Multidisciplinary Postgraduate Program in Environmental Sciences, Autonomous University of San Luis Potosí, San Luis Potosí, Mexico

${ }^{2}$ Desert Zone Research Institute, Autonomous University of San Luis Potosí, San Luis Potosí, Mexico

${ }^{3}$ Faculty of Social Sciences and Humanities, Autonomous University of San Luis Potosí, San Luis Potosí, Mexico

*Corresponding author; e-mail: claudia.heindorf@tutanota.com

\begin{abstract}
More than Maize, Bananas, and Coffee: The Inter- and Intraspecific Edible Plant Diversity in Huastec Mayan Landscape Mosaics in Mexico. Global emergencies such as biodiversity loss and climate crisis urge us to identify and mainstream crop genetic resources in complex indigenous farming systems to understand their role as genetic reservoirs and identify synergies in productive landscapes between development, conservation, and food security. We aimed to characterize the inter- and intraspecific diversity of food plants of the Tének (or Huastec) in Mexico and their distribution within and between the different land-use systems along a tropical altitudinal gradient. Tének farmers manage a highly diverse and dynamic food biota in swidden maize fields, agroforestry systems, and home gardens. Even with a small sample size, our study provides a complete analysis of the food crop diversity in the research area. The Tének cultivate a high number of 347 registered species and variants, most of them at medium altitude. Intraspecific diversity dominates (69\%). All land-use systems of the agroecosystem complex serve as a specific pool for plant genetic resources, and there is a low similarity between and within systems and localities, especially at the intraspecific level. The proportion of rare and unique food plants is high. We recommend an agroecosystem approach and prioritization for conservation as well as other efforts related to the in situ crop genetic capital.
\end{abstract}

\begin{abstract}
Más que maíces, plátanos y café: La diversidad inter e intraespecífica de plantas comestibles en los mosaicos de paisaje de los mayas huastecos en México. Las emergencias globales como la pérdida de biodiversidad y la crisis climática obligan a identificar y a reconocer los recursos fitogenéticos en los sistemas complejos agrícolas indígenas, para comprender su papel como reservorios genéticos e identificar sinergias en los paisajes productivos entre el desarrollo, la conservación y la seguridad alimentaria. El objetivo fue caracterizar la diversidad inter e intraespecífica de plantas alimenticias de los Tének (o Huastecos) en México y su distribución dentro y entre los diferentes sistemas agrícolas a lo largo de un gradiente altitudinal. Los agricultores Tének manejan una biota alimentaria muy diversa y dinámica en milpas, sistemas agroforestales y huertos familiares. Aun con el tamaño de muestra pequeño en este estudio, se proporciona un análisis completo de la diversidad de cultivos alimentarios en el área de estudio. Los Tének cultivan un elevado número de 347 especies y variantes registradas, la mayoría de ellas en la altitud mediana. La diversidad intraespecífica (69\%) es dominante. Todos los sistemas de manejo del complejo agroecosistémico sirven como reserva específica de recursos fitogenéticos, y existe una baja similitud entre y dentro de los sistemas y localidades, especialmente en el nivel intraespecífico. La proporción de plantas alimenticias raras y únicas es alta. Se recomienda un enfoque agroecosistémico y de priorización para la conservación y otros esfuerzos relacionados con el capital genético de cultivos in situ.
\end{abstract}

\footnotetext{
${ }^{1}$ Received 16 November 2020; accepted 12 May 2021; published online 9 July 2021
}

${ }^{1}$ Submitted 27 October 2020; Accepted 29 March 2021. 
Key Words: Agrobiodiversity, Ethnobotany, Home garden, Indigenous, Land-use system, Milpa, Te'lom.

Palabras Clave: Agrobiodiversidad, Etnobotánica, Huerto, Indígena, Sistemas agrícolas, Milpa, Te’lom.

\section{Introduction}

The Huastec Mayan farming landscape is a mosaic of different traditional land-use systems that consists of milpas (swidden maize farming systems), home gardens, and agroforestry systems mainly dedicated to coffee plantations (fincas) and fruit tree production (te'loms) (Alcorn 1984; Heindorf et al. 2019). Such traditional land-use systems are a reservoir of plant genetic resources, the backbone for secure agricultural food production (Altieri and Merrick 1987; Thrupp 2000). They are mainly managed by small-scale farmers who interact with the environment based on gained experiences and knowledge throughout generations (Stolton et al. 2006). These farmers usually do not have access to scientific information, external inputs, capital, credit, and developed markets (Altieri and Merrick 1987).

Traditional land-use systems are very often the origin of landraces and variants of important food crops or serve as a refuge for crop wild relatives from the natural surroundings (Galluzzi et al. 2010; Stolton et al. 2006; Thrupp 1998). They usually have a high plant diversity in time and space (Stolton et al. 2006; Toledo et al. 2003). The cultivation of a wide range of different crops contributes to the diversification of the farmer household diets (Kremen et al. 2012) and supports the functionality of the whole production system (Girardello et al. 2019). The efficient use of crop variants that cope with diverse and often adverse conditions is a risk-minimizing strategy of farmers to assure food production (Stolton et al. 2006; Toledo et al. 2003). Yet current tendencies to abandon agriculture and emphasize the use of modern or commercial variants threaten the continuation of their role (e.g., Swaminathan 2000; Wale 2011).

Even though the value of traditional land-use systems for maintaining genetic diversity is widely acknowledged (e.g., Agbogidi and Adolor 2013; Altieri and Merrick 1987; Gbedomon et al. 2017), only a few studies have included information on intraspecific diversity to strengthen this argument and to assess agrobiodiversity in traditional land-use systems comparatively (e.g., Gbedomon et al. 2017; Heindorf et al. 2019). Except for the work by Heindorf et al. (2019), which describes the rich intraspecific agrobiodiversity of the Tének milpas, the overall inter- and intraspecific diversity, including te'loms and home gardens managed by the same farmer, has not been characterized nor is its role understood.

We aimed to document the total specificand intraspecific food crop diversity in the agroecosystem complex (home gardens, milpas, agroforestry systems) of the Huastec Mayans (or Tének) and to describe the similarity within and between the different land-use systems. We also discuss changes in food plant richness.

\section{Methods}

\section{RESEARCH Site}

The Tének (or Huastec) are a Mayan people who have inhabited the Huasteca region in the eastern part of the state of San Luis Potosí in northeastern Mexico for at least 3000 years (Alcorn 1984). As previous studies show, they are knowledgeable managers of plant diversity for different purposes (e.g., Alcorn 1984; Heindorf et al. 2019). This study on the inter-and intraspecific edible plant diversity is part of a larger research project for which three Tének localities along an altitudinal gradient were selected; the same localities are considered here (Heindorf et al. 2019) (Fig. 1).

The most important locality-selection criteria were the persistence of the Tének language, the practice of subsistence agriculture, and the variety in altitude $(\mathrm{m})$ among the three sites (see Heindorf et al. 2019). The climate in the three selected research sites ranges from subtropical to tropical, and the vegetation changes from the tropical deciduous forest in research site Poytzen at low altitude (LowAlt, 59-67 m) to tropical rainforest and cloud forest in Jol Mom at medium altitude (MedAlt, 533-725 m) and cloud forest and oak-pine forest 

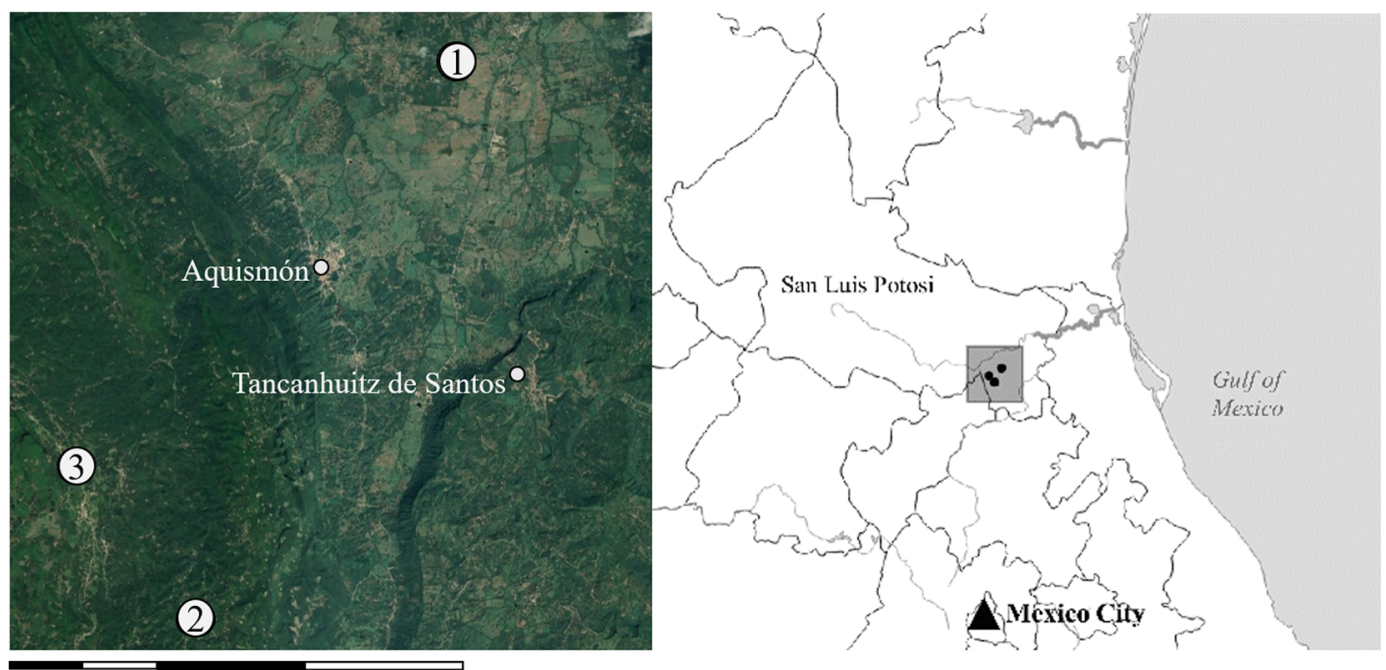

\begin{tabular}{lllll}
\hline 0 & 5 & 10 & 20 & $30 \mathrm{~km}$
\end{tabular}

Fig. 1. Three research localities along a tropical altitudinal gradient in the Huasteca Potosina, Mexico. 1: A. Poytzen (59-67 m), 2: Unión de Guadalupe (829-1180 m), 3: Jol Mom (533-725 m)

in Unión de Guadalupe at high altitude (HigAlt, 825-1180 m) (Fig. 1).

\section{Data Collection and InVEnTory}

To select the research sites we focused on Tének communities with a high percentage of indigenous language speakers and subsistence farmers, in three different altitudes. We applied purposive sampling in combination with snowball sampling to select farmers as key informants. The most important selection criteria regarding the key informants were that they had to be small-scale Tének farmers who manage and cultivate plants in the three most representative production systems: (1) milpas, (émlom in Tének), which are mainly swidden polyculture maize-based fields; (2) home gardens (eléb, kalumlab), which are agroforestry systems close to the house; and (3) te'loms, which can be described as agroforestry systems consisting of patches of secondary forest usually mixed with fruit trees and coffee plants in combination with high-value crops like vanilla (Vanilla planifolia) and chili (Capsicum spp.), and other perennial and annual crops. Te'loms that are mainly dedicated to coffee production are also named fincas (kapéjlom) (Fig. 2).

Even when almost all family units in the three research localities manage at least one of the landuse systems, the $33 \mathrm{key}$ informants were selected
(10 in LowAlt, 12 in MedAlt, and 11 in HighAlt) because they actively managed all three land-use systems at the time of our data inventory. Some common characteristics among the selected farmers were a high number of years of farming experience, a lower education grade, and a focus on subsistence farming (see also Electronic Supplementary Material (ESM) 1 for more information on key informants).

The inventory methods varied according to the land-use system: a) Milpas: each milpa was visited at least twice to inventory all crop species that change according to the different harvest cycles of the year. After an explorative walk with the farmer, each field was divided into different units (according to the main crops) and a relevé sampling method applied. Depending on the size and heterogeneity of the units, three to eleven nested sample plots were randomly selected and all species and variants were counted. The final size of each sample plot ranged from 2 to $16 \mathrm{~m}^{2}$ and was defined according to the species-area relation method (Mueller-Dombois and Ellenberg 1974). Trees and shrubs, often only sparsely distributed in the milpa fields, were all counted separately (see Heindorf et al. 2019). b) Home gardens: All the edible plants were counted. For dense herbaceous vegetation (e.g., Capsicum annuum), sample plots of $1 \mathrm{~m}^{2}$ were arranged randomly to estimate the number of plant 


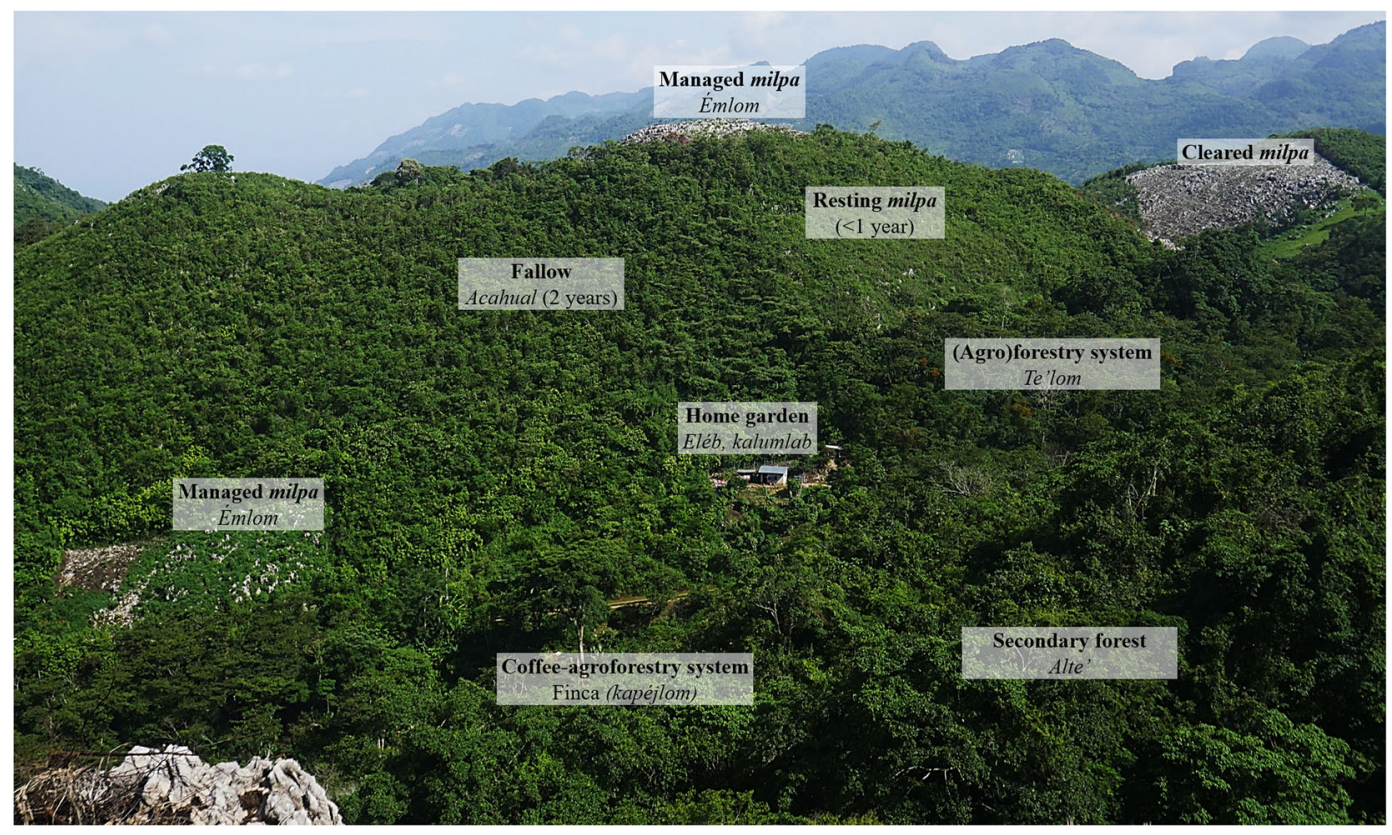

Fig. 2. The Tének landscape mosaic consists of different land-use systems (gray boxes) in the Huasteca Potosina, Mexico. Commonly, one farmer manages all these production systems throughout the year

individuals. c) Te'loms and fincas: Due to their extended size (mostly $>1$ ha and up to 4 ha) and the sparsely distributed groups of edible plants, farmers were asked to guide the researchers to each of these patches of edible plants to register the number of individuals of the species and variants. The farmers were also asked to provide the original number of trees and shrubs planted, which was useful when sample plots were impossible to establish due to difficulties to access the terrain.

Reference specimens of each species were collected for identification and deposited in the Herbarium SLPM at the Autonomous University of San Luis Potosí (http://slpm. uaslp. $\mathrm{mx} /$ ). Information on intraspecific diversity was mainly elicited from farmers, who named their variants during field inventories. Specified questionnaires were applied in a second key informant interview about the edible food plants to doublecheck the information. Even though most of the key informants were male $(84.8 \%)$, farmers' wives participated in the questionnaires and were helpful for plant identification. A photo collection of all edible plants and their variants was used to discuss naming and identification with seven expert farmers, which aimed to avoid over- and under- estimation of intraspecific diversity due to inconsistency in naming. Also, two participatory workshops were held at each locality and one seed fair was organized to discuss names of farmer-recognized species and variants. All names were documented in both local Spanish and Tének.

The edible plant diversity refers to all farmer-recognized species and variants. For this research, variants from the three research sites were considered the same when they shared the same name and labels and had no clear contrasting traits. The acronym "FVar" refers to farmer-recognized variants and "FSpe" to farmer-recognized species with no documented intraspecific variation. The total farmer edible plant diversity is expressed as "FVar+FSpe." Total botanical species refers to FSpe plus the species that correspond to the FVar.

\section{ANALYSIS OF Diversity AND Richness}

For each land-use system of each farmer, the Simpson diversity index was determined separately for the total edible plant diversity ("FVar+FSpe") and farmer-recognized variants ("FVar"). We chose the Simpson diversity 
index due to its sensibility to dominance (Magurran 2004).

The Simpson diversity index $(D$, Magurran 1991) was calculated as:

$D_{F V a r+F S p e}=1-\sum\left(\frac{\mathbf{n}_{i}}{\mathrm{~N}}\right)^{2}$

where

$\mathrm{n}_{i} \quad$ number of individuals of the $\mathrm{i}-\mathrm{th}$ FVar+FSpe;

$\mathrm{N}$ total number of individuals of FVar+FSpe; and

$D_{F V a r}=1-\sum\left(\frac{\mathrm{n}_{i}}{\mathrm{~N}}\right)^{2}$

where

$\mathrm{n}_{i} \quad$ number of individuals of the $\mathrm{i}$-th FVar;

$\mathrm{N}$ total number of individuals of FVar.

An ANOVA was performed to compare the means of edible plant richness and the D-index between different land-use systems for the three sites. Normal distribution was examined using the Shapiro-Wilk Test. In the case of a normal distribution, a Brown-Forsythe ANOVA was calculated followed by a Holm-Sidak post hoc test to determine differences between the groups. For nonnormal distribution, a Kruskal-Wallis ANOVA on ranks was used followed by Dunn's multiple comparison method.

\section{Diversity Distribution}

A rank abundance curve shows the distribution of edible plant richness in the three systems (Magurran 2004). To complement the description of the different land-use systems in terms of FVar+FSpe composition, the Similarity Percentage (SIMPER) analysis identified the FVar+FSpe that contributed most to the similarity of the same system and dissimilarity between the different landuse systems. The SIMPER analysis is based on the Bray Curtis measure of similarity (Clarke 1993).

\section{Proving Sampling Completeness}

To prove the approached sampling completeness, rarefaction curves (Mao Tao) for the different landuse systems and localities were obtained (Colwell et al. 2004). To provide information on the number of samples needed for completeness $(y=0)$, a linear extrapolation was made via linear correlation using the last 10 values of the output data (with slope = difference in the number of new taxa between samples) of the rarefaction curves. This method is used as an alternative to extrapolations proposed by other authors; for example, the analytical formula and simulation by randomizing the samples with EstimateS (Colwell et al. 2012; Ugland et al. 2003), where extrapolations are suggested that assume that sample completeness is not likely to be achieved ( $\mathrm{y}$ always $>0$ ). However, because sampling was made in an agricultural environment and the sampled taxa refer to FVar+FSpe that are known by the farmers and are mainly cultivated, the probability of new taxa is expected to be lower in contrast to natural environments, where the uncertainty inhibits predictability. Therefore, in this research, as an alternative, the linear equation correlation model is used for extrapolation, which is:

$$
\begin{gathered}
0(\text { number of new taxa })= \\
\mathrm{m}(\text { number of samples needed for completeness, } \mathrm{n})+\mathrm{b}
\end{gathered}
$$

where $\mathrm{m}$ is the slope and $\mathrm{b}$ the intercept.

A subsequent equation was used to determine the number of FVar+FSpe that would be inventoried to complete the number of samples necessary to achieve sampling completeness:

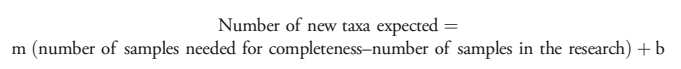

All three analyses, i.e., ANOVA, correlations, and multiple regressions, were performed with Sigma Plot V. 14.0 (https://systatsoftware.com/). Diversity indices and the rarefaction curves were calculated with Past 3.20. The SIMPER analysis was conducted using CAP 6 from PISCES (http://www. pisces-conservation.com/).

\section{Results}

The total size of the land-use systems included in the inventory was 66.3 ha of which te'loms covered $46.8 \mathrm{ha}$, followed by land used for milpas (15.1 ha), and home gardens ( $4.3 \mathrm{ha})$. The non-managed land and fallows have a surface of 74.4 ha and were not included in the inventory because usually they are not used to collect or cultivate food crops. Key informants hold on average 4.3 ha, of which 2.0 ha are under cultivation and managed. Home 
gardens are the smallest land-use system and have an average of $0.13 \mathrm{ha}$, followed by the milpas and te'loms with 0.46 ha and 1.4 ha, respectively. Sizes vary between the different localities (Electronic Supplementary Material [ESM] 1).

\section{General Description of Richness And DIVERSITY}

In the Tének milpas, home gardens, and te'loms, we registered 149 botanical species that consist of 108 genera and belong to 53 plant families, for a total of $347 \mathrm{FVar}+\mathrm{FSpe}$ consisting of $109 \mathrm{FSpe}$ and 238 FVar (Fig. 3; ESM 2). The total number of FVar+FSpe includes commercial varieties (e.g., Costa Rica coffee [Coffea sp.] and wild ancestors of cultivated plants (e.g., wild chili [Capsicum annuum var. glabriusculum]). FVar comprise $68.6 \%$ of the total FVar+FSpe, highlighting the dominance of intraspecific diversity.

For the MedAlt locality, a total of 244 FVar+FSpe were registered, followed by HigAlt and LowAlt with 203 and 175 FVar+FSpe, respectively. The highest numbers of FVar+FSpe for each land-use system were documented for the home gardens (243 FVar+FSpe) (Fig. 3). The MedAlt locality shows the highest number of FSpe and FVar for each land-use system; in particular, the number of $\mathrm{FVar}+\mathrm{FSpe}$ are considerably higher in the home gardens (166) and milpas (129). This locality also has the major richness of botanical species in home gardens and milpas. The LowAlt locality has the lowest richness for milpas and te'loms. The number for the home garden is almost equal for LowAlt (119) and HigAlt (118).

The Simpson index $(D)$ for the FVar+FSpe is slightly higher than for the FVar for each system in the three altitudes (ESM 3). The milpas have, on average, the lowest values of the diversity of FVar+FSpe $(D=0.52)$ and FVar $(D=0.48)$. It is also the only crop production system with statistically significant differences between the means of the other two research sites. The Simpson index of the milpa FVar+FSpe is statistically significantly higher for the MedAlt $(D=0.67)$. No statistically significant difference for the D-FVar was found between the different land-use systems for each of the three altitudes.

The home gardens show the highest diversity in the three different localities, with a total DFVar+FSpe average value of 0.81 and D- FVar average value of 0.74 . A comparison between production systems for the different altitudes (lower part ESM 3) shows that both for FVar+FSpe and FVar, home garden values are significantly larger than those for milpa and te'lom.

However, the standard deviation (SD) values are rather high (except for the home gardens, as expressed by high coefficients of variation (> 31\%)

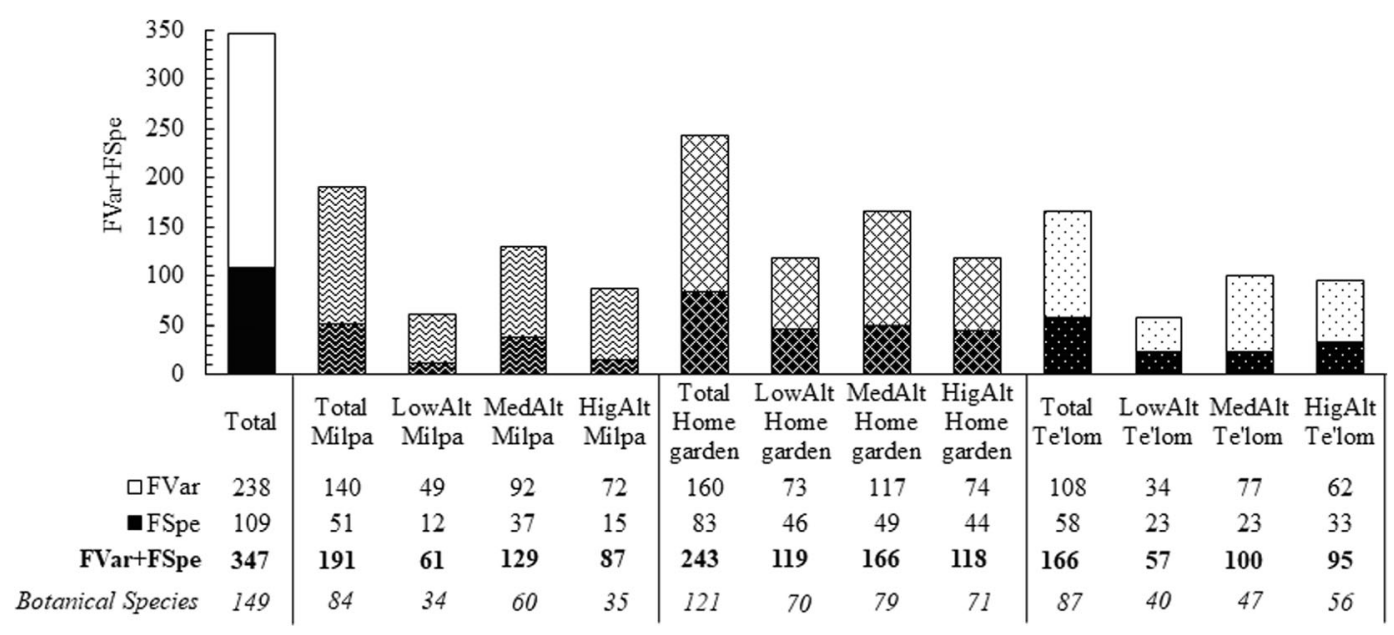

Fig. 3. The richness of edible plants in three Tének localities with different altitudes in the Huasteca Potosina, Mexico. LowAlt $=$ Low altitude $($ A. Poytzen $)$, MedAlt $=$ Medium altitude (Jol Mom), HigAlt $=$ High altitude (Unión de Guadalupe). FVar+FSpe $=$ the total farmers' edible plant diversity consisting of FVar $=$ farmer-recognized variants and FSpe $=$ farmer-recognized species with no documented variants. 
obtained from the data, which points at a high variability of the biodiversity indexes for the different systems of each farmer (ESM 3).

\section{Distribution of Edible Plant Diversity in THE Different Land-Use Systems AND LOCALITIES}

The rank abundance curves show that the total FVar+FSpe is unevenly distributed (Fig. 4). The median value of the abundance is 17 plants per species and ranges from 1 (e.g., Passiflora hahnii $[$ pux luk]) to 159,290 (Zea mays [yellow local short-cyclemaize]). Only $12.7 \%$ of all the FVar+FSpe consist of more than 1000 plants. Annual crops in the milpa, like $Z$. mays and Phaseolus vulgaris, are most abundant and make up $74.2 \%$ of the total number of plants cultivated. More than a third FVar+FSpe (125), most of them in the home garden, consists of less than 10 plants per species. The curves also show that the FVar+FSpe of the home gardens are more evenly distributed compared to the milpas and te'loms. Plant numbers in home gardens range from 1 (e.g., Spondias purpurea [yellow Campechana plum]) to 1028 (e.g., Coffea sp. [local red shade-tolerant coffee]).

\section{Richness Per Farmer and Land-Use System}

Farmers manage and cultivate on average 33.3 edible botanical species and 48.7 FVar+FSpe in their agroecosystem complex (ESM 4). The proportion of FVar to FVar+Fspe managed by each farmer is high $(71 \%)$. Farmers in MedAlt manage the highest richness of both FVar+FSpe (60) and FVar
(44) and the values are significantly higher than those of LowAlt and HigAlt. However, no significant difference was found in botanical species between the three different altitudes (ESM 4).

Concerning the richness of edible plants per farmer in the different land-use systems, significant differences exist only for the milpas between MedAlt and the two other localities. For the other two landuse systems, even though farmers in the MedAlt cultivate a higher inter- and intraspecific richness, the differences are not significant compared to the other two localities. Numbers also show that, in terms of richness of FVar+FSpe and FVar, home gardens have the highest values ranging from 2 to 60 and 2-46, respectively. Again, the range of farmers' food plant diversity varies greatly, as indicated by the high SD-values at the farmer level.

\section{Uniqueness and Shared Edible Plant \\ Diversity AMONG FARMERS, LOCALITIES, AND Production Systems}

Most of the total 347 FVar+FSpe (74.1\%) are considered rare and are cultivated in less than 30\% of all the inventoried systems (Fig. 5). Almost a quarter $(24.8 \%)$ of the total FVar+FSpe are registered just once, and only a very small portion $(1.2 \%)$ is commonly found and cultivated in more than $60 \%$ of all the systems. Results are similar regarding the frequency of FVar+FSpe separately for the milpas, home gardens, and te'loms. In all cases, more than half of the FVar+FSpe are considered as rare. The portion of FVar+FSpe that is only listed once is less, but considerable, and ranges from $35.4 \%$ in home gardens to up to $39.8 \%$ in milpas,
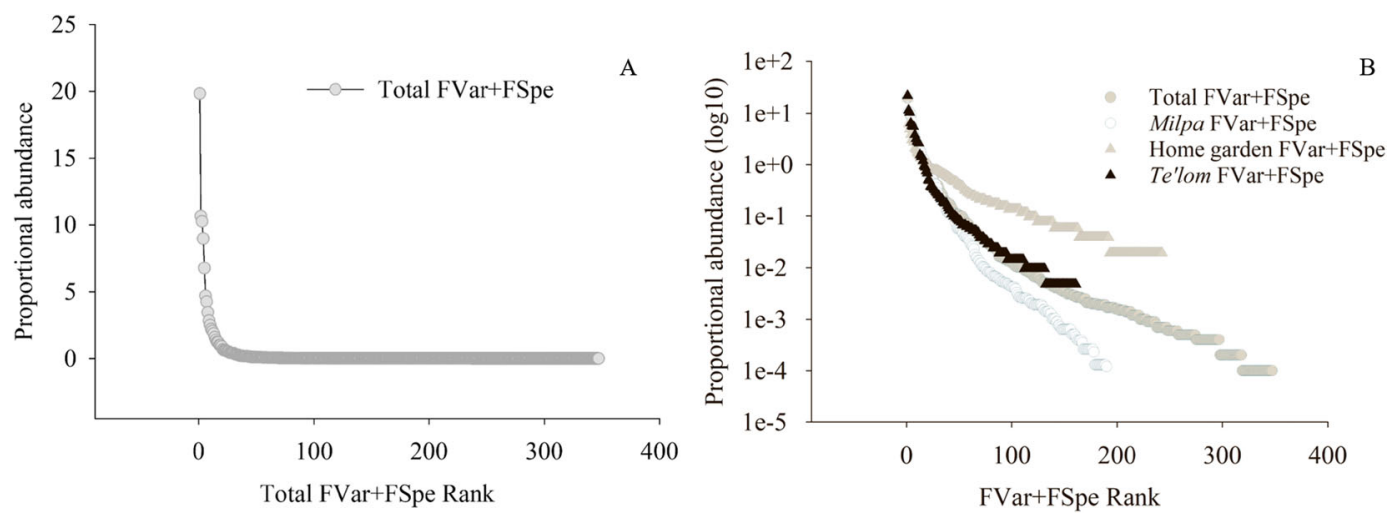

Fig. 4. Rank-abundance curve of the edible plant diversity of three Tének land-use systems in the Huasteca Potosina, Mexico. a Rank of total FVar+FSpe (linear scale) b Rank of FVar+FSpe for each land-use system (log scale). 


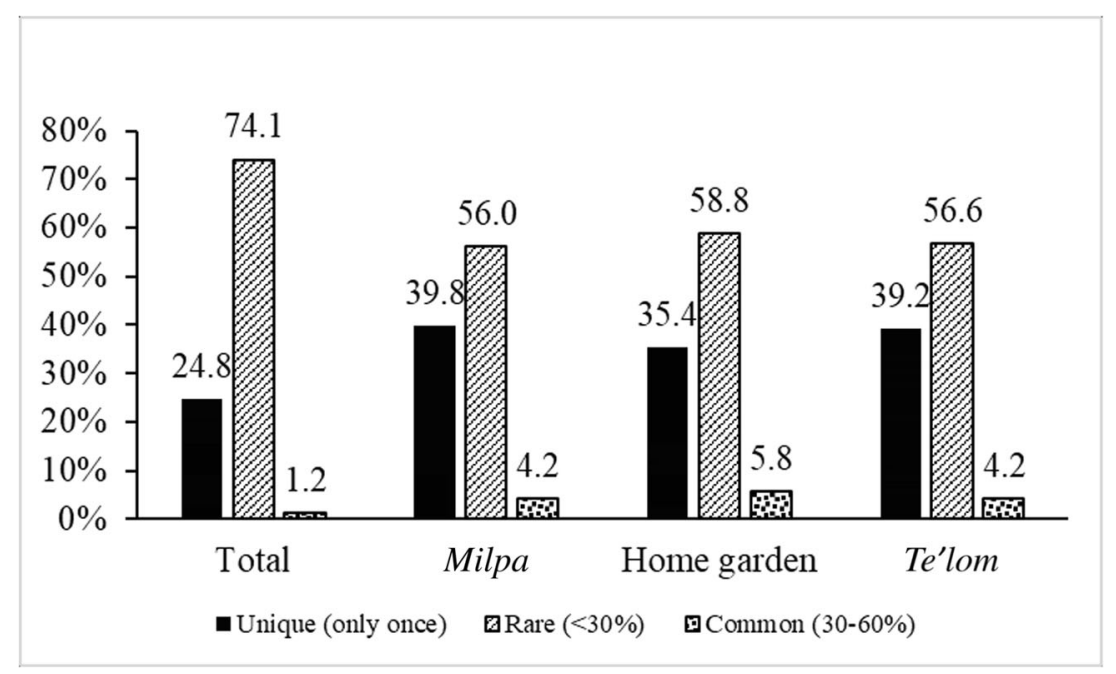

Fig. 5. The relative distribution of edible plant diversity in the land-use system complex of Tének farmers in the Huasteca Potosina, Mexico

and only a small portion $(<6 \%)$ is commonly found in the different land-use systems (Fig. 5).

The shared edible plants between the different land-use systems of the same farmer are rather low, indicating the different specific production purposes of each land-use system (Table 1). On average, only $0.4 \mathrm{FVar}+\mathrm{FSpe}$ are cultivated by a farmer in all three systems. Examples include FVar of Musa sp., Capsicum annuum, and FSpe Vanilla planifolia. Milpas and te'loms share on average 1.2 FVar+Fspe (e.g., FVar of Capsicum annuum). Home gardens and te'loms share most of the edible plants with an average of 3.4 (e.g., FVar of Citrus spp. and Musa sp.). Milpas and home gardens share $2.3 \mathrm{FVar}+\mathrm{Spe}$ (e.g., FVar of Amaranthus hybridus and Carica papaya) (Table 1). A list of more examples is provided in ESM 5.

Considering the total FVar+FSpe that are shared between different land-use systems among the three different localities, it shows that only $19.3 \%$ (67) of the total FVar+FSpe were documented in all three land-use systems (Fig. 6). Most of the FVar+FSpe were found in both home gardens and te'loms $(38.3 \%, 133)$. The number of shared FVar+FSp between milpas and home gardens is also high $(32.3 \%, 112)$. Te'loms and milpas share only $22.1 \%(75)$.

Regarding the shared FVar+Spe between home gardens and te'loms among the three localities at different altitudes, it shows that MedAlt and HigAlt share most of the FVar+FSpe (Fig. 6). Furthermore, the land-use systems in the MedAlt locality share most of the edible plant diversity with the two other localities at LowAlt and HigAlt. Figure 6 also shows that most of the home garden and milpa plants are exclusively found at MedAlt (57, 34.3\% and 65, $34.0 \%)$. In the case of the te'loms, HigAlt has the highest proportion of unique FVar+FSpe (37, $38.9 \%)$.

\section{Typifying FVar+FSPE and Similarity BETWEen AND WITHIN THE LAND-Use Systems}

Even though the different land-use systems share some portion of the same FVar+FSpe (Fig. 6), the dissimilarity between the different land-use systems is high. The Bray Curtis dissimilarity measure for the botanical species is $99.91 \%$ for milpas and home gardens, $99.90 \%$ for milpas and te'loms, and $89.82 \%$ for home gardens and te'loms (ESM 6).

The most important discriminating species that contributes in percentages to the dissimilarity between home gardens and te'loms is Coffea sp. (45.93\%), which is more abundant and frequent in the te'loms; it is also a clear discriminating species between milpa and te'loms (35.21\%). Even though milpas and home gardens share $112 \mathrm{FVar}+$ Spe (Fig. 6 ), the dissimilarity between the two groups is practically the same as between milpas and teloms that share only 75 FVar+FSpe. This is explained by the variance of the abundance of shared FVar+FSpe. However, no clearly defined discriminating species 
TABLE 1. THE AVERAge NUMBER OF SHARED EDIBLE PLANT DIVERSITY BETWEEN THE DIFFERENT LAND-USE SYSTEMS OF THE SAME FARMER IN THREE TÉNEK LOCALITIES IN MEXICO

\begin{tabular}{lccc}
\hline \hline Home garden and te'lom & $\begin{array}{l}\text { Milpa and } \\
\text { home garden }\end{array}$ & Milpa and te'lom & Between all the systems \\
\hline $3.4(3.2) \mathrm{a}^{1}$ & $2.3(3.3) \mathrm{ab}$ & $1.2(1.8) \mathrm{bc}$ & $0.4(1.1) \mathrm{c}$ \\
\hline${ }^{1}$ Means within a row followed by a different letter are significantly different from each other $(P<0.05)$. The standard deviation \\
of the means is presented in brackets
\end{tabular}

exist between those two land-use systems, indicated by the lower percentage of contribution to the dissimilarity of the first-ranked discriminating species (Zea mays: $17.72 \%$ and Musa sp.: 14.28\%), but also by the low average increase of the cumulative percentage value, which is 1.49 . Furthermore, most of the discriminating species in each pair of landuse systems that were compared vary in the average
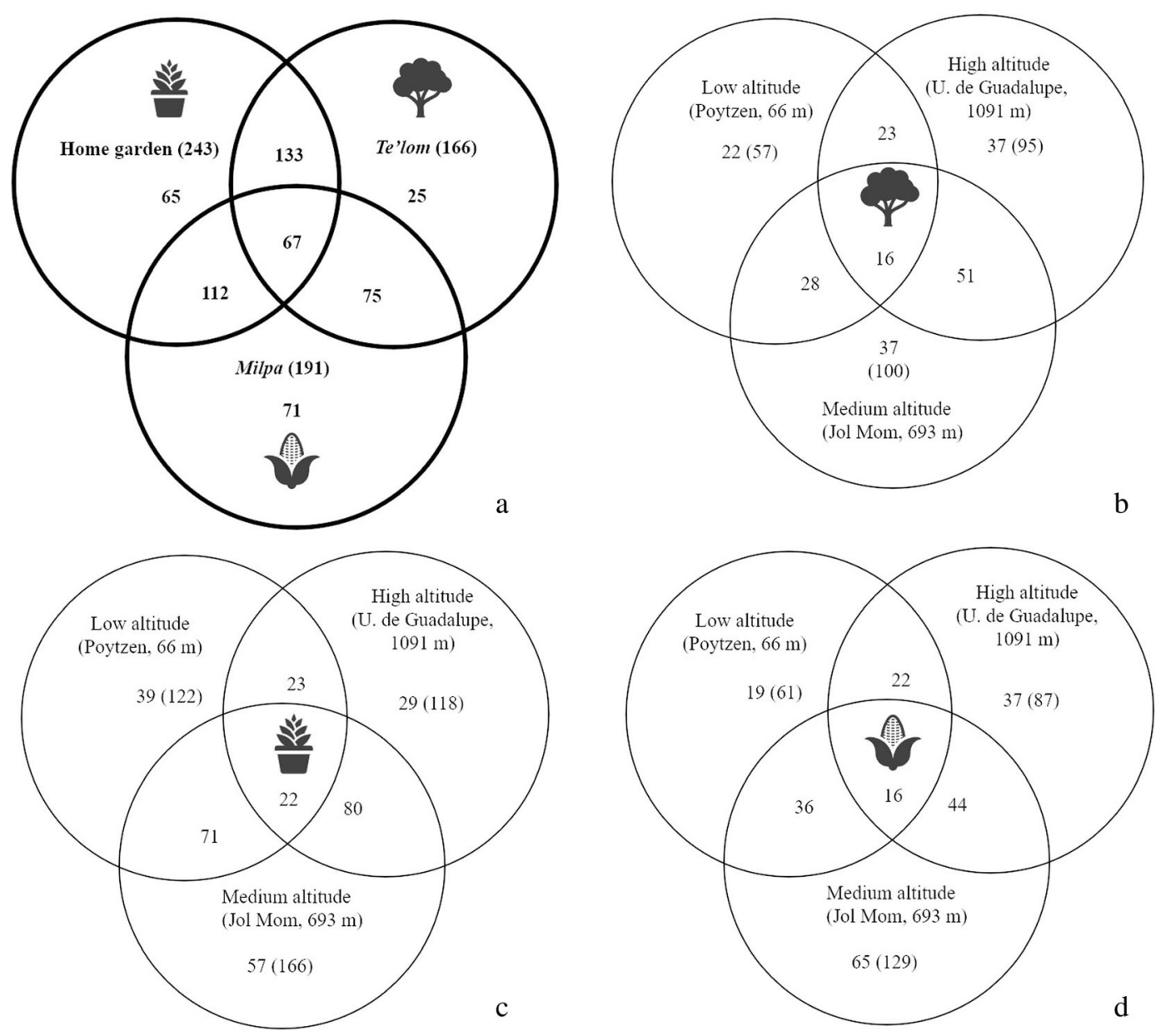

Fig. 6. Shared FVar+FSpe between the different land-use systems of three Tének localities in the Huasteca Potosina, Mexico (a), and shared FVar+FSpe between te'loms (b), home gardens (c), and milpas (d). Information on milpas was taken from Heindorf et al. (2019). The numbers in brackets refer to the total of FVar+Spe. FVar+FSpe = the total farmers' edible plant diversity, consisting of FVar $=$ farmer-recognized variants and FSpe $=$ farmer-recognized species with no documented variants. 
abundance value (e.g., Phaseolus vulgaris in milpas: 3271.98 compared to $P$. vulgaris in home gardens: 0.36) (ESM 6).

The composition of species varies also within the same land-use system, as shown by the relatively low average similarity values. The average similarity of all the inventoried milpas is $39.62 \%$. Similarities are lower among te'loms $(23.42 \%)$ and home gardens (26.73\%).

Only five species of the milpas are the main contributors to similarity within the group. The most important one is Zea mays $(72.46 \%)$. In the case of the home gardens, 22 species contribute to similarity. The most important is Musa sp. $(24.06 \%)$. For the te'lom, the most contributing species is Coffea sp. (49.96\%). The complete list of species that contribute to similarity within the groups is presented in ESM 7.

The similarity of the FVar+FSpe composition within the different land-use systems at the different altitudes is even lower (Table 2), which shows that the farmer's preferences in terms of FVar+FSpe composition vary considerably at each locality. However, even though similarity values are low, SIMPER analysis can determine some patterns in terms of the composition of edible plant diversity for the land-use systems at different altitudes. $<\mathrm{TAB} 2>$.

Furthermore, FVar+FSpe that typify most of the different land-use systems vary in number and percentage of contribution to similarity within each group (Fig. 7). For example, for the milpas, only two typifying FVar+FSpe in LowAlt, three in HigAlt, and five in MedAlt were identified, which shows that farmers in this land-use system focus on the production of a few specific FVar+FSpe. An example is the yellow short-cycle local maize in the LowAlt with $81.63 \%$ of contribution to similarity within this group (Fig. 7; ESM 8).

For all milpas at different altitudes, a maize variant is the first-ranked typifying crop (ESM 8). However, for the maize variants in MedAlt and HigAlt, the percentage of contribution is considerably lower, with $30.64 \%$ and $49.52 \%$, respectively. Furthermore, in HigAlt, the first ranked $\mathrm{FVar}+\mathrm{Spe}$ includes a preferred maize variant that is different from those of the other localities (white short-cycle local maize). For the home gardens and te'loms, the number of FVar+FSpe that contribute to similarity within each land-use system at different altitudes is higher. For the home gardens, numbers range from 17 FVar+FSpe in HigAlt to 29 FVar+FSpe in MedAlt (Fig. 7). For the te'loms, numbers range from $8 \mathrm{FVar}+\mathrm{FSpe}$ in LowAlt and HigAlt to 14 FVar+FSpe in MedAlt. Farmers at LowAlt have a clear preference for the Jamaica banana (Musa sp. [50.80\%]), while farmers in HigAlt cultivate mostly the Manila banana (19.01\%). For MedAlt, even though different variants of banana are counted as typifying crops, the first-ranked typifying crop for the home garden is the wild chili (Capsicum annuum var. glabriusculum [21.9\%]).

Concerning the te'loms, a different production strategy is demonstrated, which is related to the number of different crop variants that were determined as typifying FVar+FSpe. The farmers in the te'loms in LowAlt focus mainly on different variants of fruit tree species. The most important one is, again, the Jamaica banana $(42.72 \%)$, followed by the Mexican lime (Citrus aurantiifolia [29.24\%]). The farmers at HigAlt mainly focus on coffee production. All the typifying FVar+FSpe are coffee variants with exception of Inga vera (4.27\%), which is also used as a shade-providing tree for the coffee plants. However, farmers in HigAlt strongly prefer yellow local coffee $(49.50 \%)$, whereas the other coffee variants have considerably lower values $(3.13 \%-16.72 \%)$. Te'loms in MedAlt do not have a clear typifying FVar+FSpe. The first six FVar+FSpe include coffee variants but also some fruit trees and chili variants. However, the contribution value of the latter two crop groups is low and ranges from $1.15 \%-2.36 \%$ (Fig. 7; ESM 8).

TABle 2. Average Similarity (\%) WITHIN THE DifFERENT LAND-USE SYSTEMS AT DifFERENT ALTITUDES CONCERNING THE COMPOSITION OF FVAR+FSPE = THE TOTAL FARMERS' EDIBLE PLANT DIVERSITY CONSISTING OF FVAR = FARMERRECOGNIZED VARIANTS AND FSPE = FARMER-RECOGNIZED SPECIES WITH NO DOCUMENTED VARIANTS

\begin{tabular}{llll}
\hline \hline & Home garden & Milpa & Te'lom \\
\hline High altitude & 8.83 & 12.89 & 14.39 \\
Medium altitude & 19.91 & 16.96 & 13.68 \\
Low altitude & 6.42 & 24.38 & 7.05 \\
\hline
\end{tabular}




\section{SAmpling Completeness}

The modified rarefaction analysis based on the linear equation model evidenced that the inventoried taxa were close to $100 \%$ of the hypothetical total for all the land-use systems in the different altitudes (ESM 9). For example, for the total taxa (347) for the three systems and three localities, our sample of 99 yields $99.6 \%$ of the hypothetical total taxa (348) if the sample would be increased to 165 .

\section{Discussion}

According to the results of this research, there are three points. (1) Compared to other data from Mexico, the Tének in the Huasteca Potosina cultivate a uniquely high diversity of foods crops at both inter- and intraspecific levels with the medium-altitude site showing the highest diversity. (2) All land-use systems that form the Tének landscape mosaic serve as a specific pool for plant genetic resources. (3) There is a low similarity between and within systems and localities, especially at the intraspecific level. We propose efforts for crop diversity conservation, promotion, and use that recognize the importance of each different land-use system as complementary agrobiodiversity reservoirs of the Huastec Mayan agricultural landscape.

\section{The High Diversity in the TéNeK Agroecosystem Complex}

As do other indigenous peoples, the Tének in the Huasteca Potosina manage different land-use systems that form the agroecosystem complex (Toledo et al. 2003), all of which show high diversity. The number of $191 \mathrm{FVar}+\mathrm{FS}$ pe for the local milpas, as already shown by Heindorf et al. (2019), clearly exceeds the number of edible milpa plants registered by other authors (e.g., Lara Ponce et al. 2012; Mateos-Maces et al. 2016). This was also the case for the richness of FVar+FSpe at farmers' level and locality level.

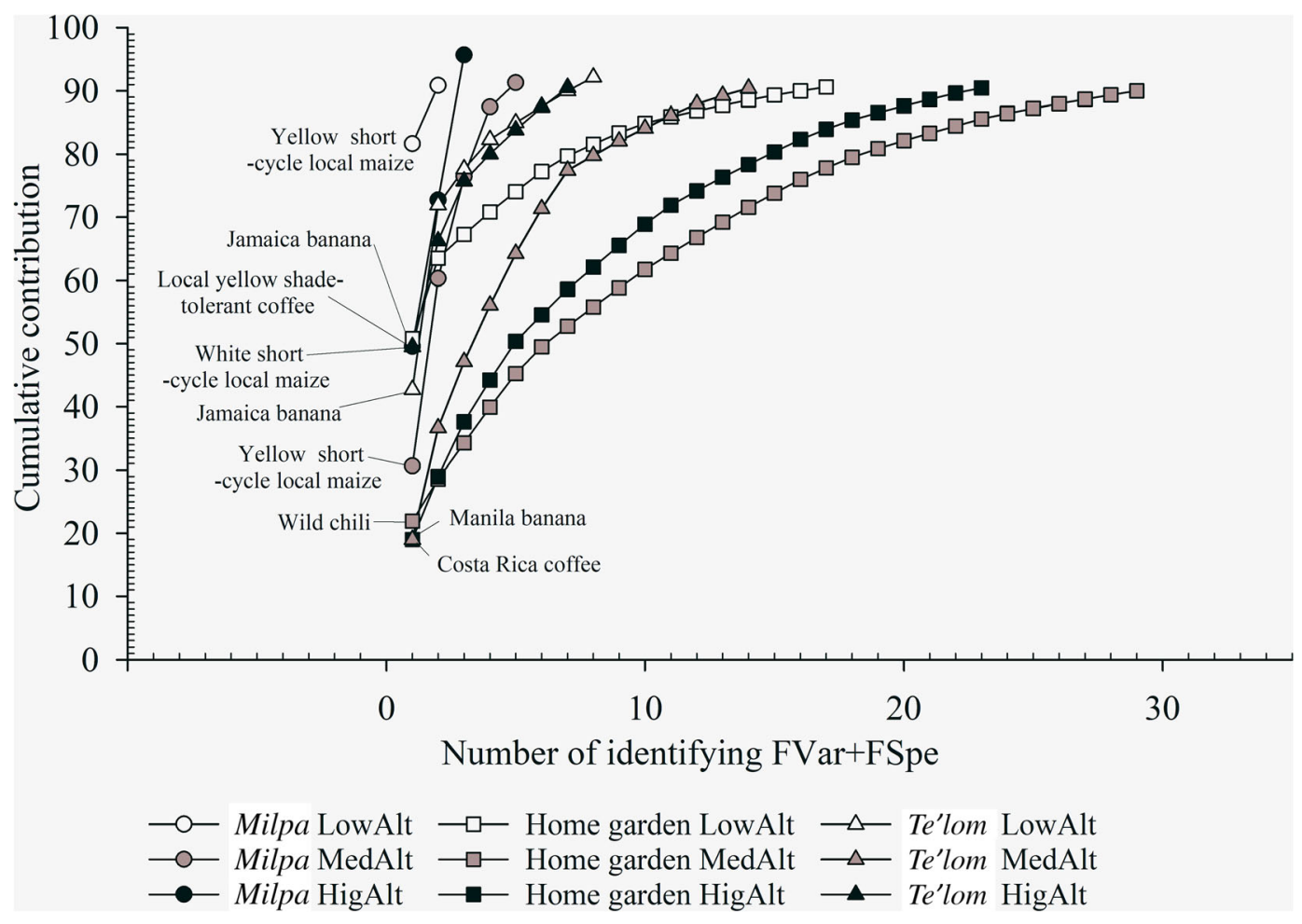

Fig. 7. The cumulative percentage and number of identifying typifying FVar+FSpe through SIMPER analysis for each land-use system and altitude (locality). FVar+FSpe = the total farmers' edible plant diversity consisting of FVar $=$ farmer-recognized variants and FSpe = farmer-recognized species with no documented variants. 
Toledo et al. (2003) provided a sum of 360 food plants that are used by a total of 10 different indigenous groups. Here, for only one ethnic group and considering data from only 33 farmers, a total of 347 FVar+FSpe were documented, which are composed of 149 botanical species. Separating the data for home gardens, Toledo et al. (2003) documented 136 edible home garden plants of the different indigenous groups. Other home garden studies in Mexico document a richness of 42-50, 40, and 60 edible plant species (Chablé-Pascual et al. 2015; Pulido-Salas et al. 2017; and Ortíz-Sánchez et al. 2015, respectively). In this study, 121 edible home garden plant species were registered.

In their meta-analysis, Toledo et al. (2003) also provide information on 168 edible food plants from the secondary forests. The secondary forests are comparable to the te'loms of the Tének, with a total of 164 FVar+FSpe registers, including 89 botanical species. In a review paper that includes over 20 studies, Ángel Martínez et al. (2007) provide a total of 129 edible plant species in coffee-agroforestry systems in Mexico, a number that consists of their data and registers of additional inventories in more than 25 municipalities.

No comparison on intraspecific food plant diversity is possible for now, since, to our knowledge, no other study has been published on intraspecific diversity in a similar agroecosystem complex. Nevertheless, an interesting comparison can be made with the work of Alcorn (1984), who documented over 900 plant species in the Tének region of the Huasteca Potosina. Out of this vast list of useful plants, 204 plant species were classified as edible plants. In our study, a total of 149 edible plant species were registered, of which 107 coincide with the plants used for food registered by Alcorn (1984) almost 40 years ago. The higher number of plants documented by Alcorn (1984) that are used for food could point to a possible loss of local knowledge on edible plants and their importance in the intervening decades, yet can also be explained by differences in focus, design, and collection effort of the two studies. Alcorn (1984) documented plants from 22 Tének localities; whereas in this study, information was gathered in only three localities, none of which was included in the study by Alcorn (1984). Furthermore, Alcorn (1984) also included food plants from non-managed environments like the forests and riversides, not considered in this study. Several plants that were listed in these nonmanaged ecosystems were also listed in milpas and te'loms, and six of them refer to plants that are used in times of food shortages, like Byttneria aculeata or Croton reflexifolius. However, in this study, the local people considered several of these plants as weeds rather than edible plants. Even though some of their parts might be edible, these plants are not consumed locally anymore, e.g., Adelia barbinervis, Guazuma ulmifolia, and Bidens pilosa, which are commonly found in the milpa and teloms.

On the other hand, 16 plant species in this study were identified by the farmers as food plants but were not listed as such by Alcorn (1984). Two of them include Hibiscus sabdarriffa and Muntingia calabura. The first is broadly used in Mexico to prepare beverages or as an ingredient for tacos de flor de jamaica and M. calabura is widely known for its edible fruits (Pennington and Sarukhán 2005). Explanations for this difference are rather speculative, but different knowledge on plant use as well as newly gained knowledge on the edibility of the plants during the last decades could be some of the reasons.

In our study, we listed 45 food plants that were not documented by Alcorn (1984). More than half (23) refer to Old World plants like Averrhoa carambola, Beta vulgaris, Litchi chinensis, and Moringa aff. oleifera, and were probably introduced more recently. This is the case, for example, of Artocarpus heterophyllus that, according to information provided by farmers in this study, was not known and cultivated in the region 10 years ago.

The simple comparison of Alcorn's lists with ours, spanning over 30 years, demonstrates that the use of food crops is dynamic. Based on the information of these studies, it would be promising to keep assessing food plant diversity dynamics in traditional Tének land-use systems in the following decades.

Interestingly, as the rarefaction curve and its extrapolation using linear regression showed, even with the high agrobiodiversity encountered here, the sample size chosen of 33 farmers allowed to inventory $99.6 \%$ of the taxa that would have been inventoried as $100 \%$ with a sample size five times larger (ESM 9). This allows us to believe that the sample size in agricultural inventories can be rather small if sufficient detailedness, such as the one used here, is applied. Yet, our study was time consuming as our fieldwork spread out over 20 field visits. During these two- to three-week visits, plant inventories in more than 99 managed land-use systems were executed, often twice to include seasonal differences in crop stock on the farm. Additionally, workshops, farmer interviews, and focus group 
discussions were undertaken. More time-efficient methods exist, for example, the Agricultural Biodiversity Assessment Method (Bellon 2017), which is based on focus group discussions, household surveys, and the four-cell method as a tool to gather abundance information. We suppose those alternative methods are advantageous and provide reliable information on crop diversity distribution at the species level, but are probably inappropriate at the intraspecific level. A comparison of our detailed in situ data collection or similar approaches with more time- and resource-efficient methods would be a valuable contribution to analyze the thoroughness of different agrobiodiversity inventory methods. This is especially important regarding the need for food crop diversity data beyond the focus on just a few major crops and on a larger geographical scale (Bellon 2017), where time- and resourceconsuming studies are impractical and careful alternative methods are needed.

\section{The Components of the Agroecosystem Complex as Pools for Plant Genetic Resources}

Almost three-quarters of the FVar+FSpe are classified as rare and $24.8 \%$ are registered only once (Fig. 5). Furthermore, diversity indexes (ESM 3) demonstrate that most of the edible plants are unevenly distributed and only a small number of FVar+ FSpe show a high abundance, all of them belonging to groups of the most important crops of the milpas or the coffee plants and banana plants, which are mainly distributed in the te'loms and home gardens. High proportions of rare species were also documented in other shifting cultivation systems and home gardens (Blanco et al. 2013; Trinh et al. 2003). Small population numbers cannot assure the persistence of genetic diversity in the farmer's cropping systems (Bellon et al. 2018; Heindorf et al. 2019) and the edible plant diversity of the Tének agroecosystem complex should receive attention in terms of the promotion and use of the edible crop diversity, especially because $68.6 \%$ of the total FVar+FSpe were identified as FVar, something that underlines the role of this particular agroecosystem complex for on-farm conservation of intraspecific diversity. Most studies of on-farm crop diversity remain on species level or, when focused on intraspecific diversity, are limited to a few selected food plants (e.g., studies about on-farm maize diversity). We would like to encourage scholars to focus on other important crop groups like, for example, Sechium edule and Cucurbita spp., both of which are less studied but also contribute to the local diet and income of the farming communities and are very common to find on local markets (Heindorf et al. 2021).

The high number of unique species with low individuals, especially in the case of fruit trees, highlights the risk of loss of the intraspecific diversity for this particular plant group. In this context, it is important to investigate how the crops are propagated; e.g., if farmers tend to focus on asexual propagation that increases the genetic vulnerability of the already small number of populations, or if they use a combination of asexual and sexual propagation that allows inter- and intraspecific hybridization and increases the genetic pool of cultivated germplasm (Bisognin 2011).

Food security efforts are made to intensify global staple crop production worldwide to assure food access and provision for a growing population. But food security also includes dietary diversity and quality of food. The sole focus on staple crop production may not cope with current food challenges. There exists a positive relationship between production diversity and dietary diversity (Ickowitz et al. 2019; Powell et al. 2015). Current food security policy majorly advocates intensification of farming systems to enhance agricultural productivity of selected staple crops resulting in homogenized crop diversity and diets. This study shows that traditional small-scale farmers cultivate a broad range of different food crops. Those farmers should be actively included in food security efforts because they play an important and active role in maintaining crop genetic resources of staples, non-staples, underutilized crops, and edible greens with different dietary benefits to the farmer families and consumers. The group of underutilized crops and edible greens include, for example, Sechium edule and Amaranthus bybridus, both with nutritious benefits for its consumers (Funke 2011; Mishra and Das 2015) and valued food crops by the Huastec farmers.

The farmers manage on average 48.7 FVar+FSpe in their agroecosystem complex. Similar to our findings on milpa diversity (Heindorf et al. 2019), the farmers in the MedAlt cultivate more FVar+FSpe with an average of 60 , compared to the farmers in the other two sites (ESM 4). However, there was no statistically significant difference in terms of species richness, but the variants' richness varies significantly between MedAlt and the other two sites. Analogous to the data on milpas, MedAlt is also the locality that shares most of the home garden and 
te'lom FVar+FSpe with the two other localities. It also hosts most of the exclusively distributed FVar+FSpe in the home gardens and milpas (Fig. 6), which are factors to consider when choosing a priority site for interventions in favor of crop diversity (Heindorf et al. 2019).

A criterion for this selection can be based on diversity indexes as shown in ESM 3, where statistically significant differences between altitudes and between production systems were established. For example, the home gardens consistently showed higher diversity indices than the other two systems, for both FVar and FVar+FSpe, yet overall population sizes of crops (mainly trees) are rather small in home gardens and this could be another criterion itself when choosing priority sites for interventions.

\section{Low SimILARITY WITHIN THE LAND-UsE SYSTEMS}

As determined by the SIMPER analysis, the similarity within the land-use systems is low, especially at the intraspecific level. Also, the dissimilarity of the species composition between the different land-use systems in paired comparisons is high, showing the heterogeneity in terms of species abundance even though several may be shared between the different systems (Fig. 6). This is probably linked to the highly different production purposes of each system (e.g., high number of coffee plant individuals in te'loms). This creates a niche for conservation purposes of the different land-use systems to assure minimum population sizes of target crops to avoid genetic decay (Bellon et al. 2018) (ESM 6). The Simpson index values underline that the production strategies of milpas and te'loms differ from the production purpose of home gardens. Plant production cycles and variants are well adapted to the different environmental conditions. While home gardens close to the house contain a lot of different species and variants with similar low abundance, milpas and te'loms contain few selected but dominant crops (e.g., Zea mays, Phaseolus vulgaris, Coffea sp.) with seasonality in production. Home gardens serve as a reservoir of a little bit of everything: as living seed banks, farmers experimentation fields, and nurseries of care-intensive plants or high-value crops (e.g., $\mathrm{Va}$ nilla planifolia, fruit trees) as well as sparsely used food plants (e.g., condiments and edible flowers [Erythrina americana]).

At the farmers' level, the number of shared FVar+FSpe is highest for home gardens and te'loms (3.4), which can be explained considering that both systems mainly consist of trees. However, the milpa also shares an average of 2.3 FVar+Spe with home gardens. Only a very small amount of the farmers' edible plant diversity is cultivated in all three systems (0.4; Table 1) and just $19.3 \%$ of the total FVar+FSpe is shared among all the three systems of the different localities (Fig. 6). Farmers have a clear preference for some selected species and variants depending on the type of land-use system and altitude (Fig. 7). The selection of appropriate species and variants is crucial, especially if farmers simultaneously manage an elevated number of crops in low input farming systems (see Bellon 1996; Heindorf et al. 2019). It reveals the in-depth knowledge of farming communities to manage crop diversity in complex agroecosystems.

This supports the argument of favoring an agroecosystem-approach for the in situ conservation of plant genetic resources, including the local knowledge and management practices. These production models serve as a vital knowledge and genetic resource base for the diversification of agricultural systems as a strategy for a more sustainable food production. Diversification brings multiple benefits by fostering synergies of the different abiotic and biotic components of heterogeneous agroecosystems, support the functionality of the farmers' production systems, and provide ecosystem services that contribute to the planet's health in general (Girardello et al. 2019; Vandermeer et al. 1998). It's also a resilience strategy to environmental and socioeconomic risks, especially in times of present and future uncertainties, e.g., the current SARS-CoV-2 pandemic and climate emergency (Duguma et al. 2021; Jackson et al. 2007). Farmers' knowledge about the management of the overall biotic and abiotic complexity of the agroecosystems, especially in terms of crop combination and planning of interventions, deserves further investigation. The importance of traditional agroecosystems for crop conservation purposes and the incorporation of farmers' local knowledge, for example to facilitate sustainable agricultural intensification, is not new (Altieri and Merrick 1987; Oldfield and Alcorn 1987); yet, it remains relevant to cope with global challenges such as biodiversity loss (including the diversity of cultivated crops and crop wild relatives).

\section{Conclusions}

Concluding, the diversity of edible crops managed by the Tének, when studied at the intraspecific 
level and applying an agroecosystem approach, reveals an extraordinary richness. The Tének agroecosystem complex, a mosaic of different land-use systems, is a valuable pool of plant genetic resources. In terms of the need to maintain this richness, both for the benefit of the indigenous communities that own it and for the growing demand in food requirements in the context of population growth and adaptation to the climate emergency, identifying and mainstreaming crop genetic resources at the intraspecific level, well beyond the commonly used interspecific level or the development of improved varieties, becomes a necessity and opportunity.

\section{Supplementary Information}

The online version contains supplementary material available at https://doi.org/10.1007/s12231021-09520-9.

\section{Acknowledgements}

We thank taxonomists Mr. José García and Dr. Eleazar Carranza of the Desert Zone Research Institute Herbarium SLPM for supporting us with species identification. We thank Maestra Gudelia Cruz, Alejandra Balderas, and Señorina Reyes for their help with the list of Tének names. We are grateful to all the key informants and households in A. Poytzen, Jol Mom, and Unión de Guadalupe for participating in this research. Special thanks to Matilde, Don Olegario, Don Plácido, Don Benigno, María Antonia, and Marie, student assistants, and Agosto and Ike.

This work was supported by CONACYT through the project "Nenek" (CB-2012-180863), a CONACYT scholarship for doctoral studies (CB2016-180193), a "Research Support Fund" from the Autonomous University of San Luis Potosí (C18-FAI-05-58.58), and the "National and International Mobility Program for Graduate Students".

The first author was mainly responsible for conducting fieldwork, research design, data analysis, and the first draft of the manuscript. J. A. ReyesAgüero supervised and designed the research project. All three co-authors reviewed the manuscript, discussed the research results, and contributed to the final version of the manuscript.

The research was undertaken respecting the ISE code of ethics. In adherence to the ISE guidelines, an educated prior informed consent to the research activities was established with the local community authorities and all key informants who participated in this study did so freely. There were no competing interests. We organized an introductory workshop for each local community to introduce our research project and organized activities to enhance the local awareness of the promotion and use of local agrobiodiversity. After completion of the study, we organized final workshops to share our research results with the local communities. The community members agreed on sharing the results with the scientific community and other members of the society.

\section{References}

Agbogidi, O. M. and E. B. Adolor. 2013. Home gardens in the maintenance of biological diversity. Journal of Advances in Biology 2:135-144.

Alcorn, J. B. 1984. Huastec Mayan ethnobotany. Austin: University of Texas Press.

Altieri, M. A. and L. C. Merrick. 1987. In situ conservation of crop genetic resources through maintenance of traditional farming systems. Economic Botany 41(1):86-96.

Ángel Martínez, M., V. Evangelista, F. Basurto, M. Mendoza, and A. Cruz-Rivas. 2007. Flora útil de los cafetales en la Sierra Norte de Puebla, México. Revista Mexicana de Biodiversidad 78(001).

Bellon, M. R. 1996. The dynamics of crop infraspecific diversity: A conceptual framework at the farmer level 1. Economic Botany 50(1):26-39. 2017. Agricultural Biodiversity Assessments in dryland systems of Ghana, India, Malawi, Mali and Niger: An overview of the framework, methods and datasets. Harvard Dataverse V1. https://doi.org/10.7910/DVN/5774FJ.

Bellon, M. R, A. Mastretta-Yanes, A. Ponce-Mendoza, D. Ortiz-Santamaría, O. OliverosGalindo, H. Perales, F. Acevedo, and J. Sarukhán. 2018. Evolutionary and food supply implications of ongoing maize domestication by Mexican campesinos. Proceedings of the Royal Society B 285(1885):20181049. https://doi. org/10.1098/936rspb.2018.1049.

Bisognin, D. A. 2011. Breeding vegetatively propagated horticultural crops. Crop Breeding and Applied Biotechnology 11:(35-43).

Blanco, J., L. Pascal, L. Ramon, H. Vandenbroucke, and S. M. Carrière. 2013. Agrobiodiversity performance in contrasting island environments: The case of shifting cultivation in Vanuatu, Pacific. Agriculture, Ecosystems \& Environment 174:28-39. 
Chablé-Pascual, R., D. J. Palma-López, C. J. Vázquez-Navarrete, O. Ruiz-Rosado, R. Mariaca-Méndez, and J. M. Ascensio-Riveral. 2015. Estructura, diversidad y uso de las especies en huertos familiares de la Chontalpa, Tabasco, México. Ecosistemas y Recursos Agropecuarios 2(4):23-39.

Clarke, K. R. 1993. Non-parametric multivariate analyses of changes in community structure. Australian Journal of Ecology 18(1):117-143.

Colwell, R. K., C. X. Mao, and J. Chang. 2004. Interpolating, extrapolating, and comparing incidence-based species accumulation curves. Ecology 85(10):2717-2727.

Colwell, R. K., A. Chao, N. J. Gotelli, S. Lin, C. X. Mao, R. L. Chazdon, and J. T. Longino. 2012. Models and estimators linking individual-based and sample-based rarefaction, extrapolation and comparison of assemblages. Journal of Plant Ecology 5(1):3-21.

Duguma, L. A., M. van Noordwijk, P.A. Minang, and K. Muthee. 2021. COVID-19 Pandemic and agroecosystem resilience: Early insights for building better futures. Sustainability 13(3): 1278. https://doi.org/10.3390/su13031278.

Funke, O. M. 2011. Evaluation of nutrient contents of amaranth leaves prepared using different cooking methods. Food and Nutrition Sciences 2:249-252. https://doi.org/10.1016/j.gfs.2018. 11.002.

Galluzzi, G., P. Eyzaguirre, and V. Negri. 2010. Home gardens: Neglected hotspots of agrobiodiversity and cultural diversity. Biodiversity Conservation 19:3635-3654. https://doi.org/ 10.1007/s10531-010-9919-5.

Gbedomon, R. C., V. K. Salako, A. B. Fandohan, R. Idohou, R. G. Kakaï, and A. E. Assogbadjo. 2017. Functional diversity of home gardens and their agrobiodiversity conservation benefits in Benin, West Africa. Journal of Ethnobiology and Ethnomedicine 13(1):66. https://doi.org/ 10.1186/s13002-017-0192-5.

Girardello, M., A. Santangeli, E. Mori, A. Chapmanb, S. Fattorini, R. Naidoo, S. Bertolino, and J.-C. Svenning. 2019. Global synergies and trade-offs between multiple dimensions of biodiversity and ecosystem services. Scientific Reports 9(1):5636. https://doi.org/10. 1038/s41598-019-41342-7.

Heindorf, C., J. A. Reyes-Agüero, J. FortanelliMartínez, and A. van 't Hooft. 2019. Interand intraspecific edible plant diversity of Tének milpas fields in Mexico. Economic Botany 73(4):489-504.

Heindorf, C., J. A. Reyes-Agüero, and A. van 't Hooft. 2021. Local markets: Agrobiodiversity reservoirs and access points for farmers' plant propagation materials. Frontiers in Sustainable Food Systems 5:14. https://doi.org/10.3389/ fsufs.2021.597822.

Ickowitz A., B. Powell, D. Rowland, A. Jones, and T. Sunderland. 2019. Agricultural intensification, dietary diversity, and markets in the global food security narrative. Global Food Security 20. https://doi.org/10.1016/j.gfs.2018.11.002.

Jackson, L. E., U. Pascual, and T. Hodgkin. 2007. Utilizing and conserving agrobiodiversity in agricultural landscapes. Agriculture, Ecosystems and Environment 121(3):196-210. https://doi. org/10.1016/j.agee.2006.12.017.

Kremen, C., A. Iles, and C. Bacon. 2012. Diversified farming systems: An agroecological, systems-based alternative to modern industrial agriculture. Ecology and Society 17(4):40. https://doi.org/10.5751/ES-05035-170440.

Lara Ponce, E., L. Caso Barrera, and M. Aliphat Fernández. 2012. El sistema milpa roza, tumba y quema de los Maya Itzá de San Andrés y San José, Petén Guatemala. Ra Ximhai 8(2):71-92.

Magurran, A. E. 1991 Ecological diversity and its measurement. Princeton, New Jersey: Princeton University Press.

- 2004. Measuring biological diversity. Malden, Massachusetts, United States; Oxford, United Kingdom; and/or Victoria, Australia: Blackwell Publishing.

Mateos-Maces, L., F. Castillo-González, J. L. Chávez Servia, J. A. Estrada-Gómez, and M. LiveraMuñoz. 2016. Manejo y aprovechamiento de la agrobiodiversidad en el sistema milpa del sureste de México. Acta Agronómica 65(4):413-421.

Mishra, L. K. and P. Das. 2015. Nutritional evaluation of squash (Sechium edule) germplasms collected from Garo Hills of Meghalaya-North East India. International Journal of Agriculture Environment and Biotechnology 8(4):971.

Mueller-Dombois, D. and H. Ellenberg. 1974. Aims and methods of vegetation ecology. New York: Wiley.

Oldfield, M. L. and J. B. Alcorn. 1987. Conservation of traditional agroecosystems. Bioscience 37(3):199-208.

Ortíz-Sánchez, A., C. Monroy-Ortiz, A. RomeroManzanarez, M. Luna-Cavazos, and P. CastilloEspaña. 2015. Multipurpose function of home 
gardens in the family subsistence. Botanical Science 93(4):791. https://doi.org/10.17129/ botsci.224.

Pennington, T. D. and J. Sarukhán. 2005. Árboles tropicales de México-Manual para la identificación de las principales especies, $3 \mathrm{~d}$ ed. Ediciones científicas universitarias. Serie Texto Científico Universitario. Mexico City: National Autonomous University of San Luis Potosi, Fondo de Cultura Económica.

Powell, B., S. H. Thilsted, A., Ickowitz, C. Termote, T. Sunderland, and A. Herforth. 2015. Improving diets with wild and cultivated biodiversity from across the landscape. Food Security 7:535-554. https://doi.org/10.1007/ s12571-015-0466-5.

Pulido-Salas, M. T., M. de Jesús Ordóñez Díaz, and H. C. de Dios. 2017. Flora, usos y algunas causales de cambio en quince huertos familiares en el municipio de José María Morelos, Quintana Roo, México. Península 12(1):119-145.

Stolton, S., N. Maxted, B. Ford-Lloyd, S. Kell, and N. Dudley. 2006. Food stores: Using protected areas to secure crop genetic diversity-A research report by WWF, Equilibrium and the University of Birmingham, United Kingdom. Gland, Switzerland: WWF.

S w a min a tha n, M. S. 20000 . Government-Industry-Civil Society: Partnerships in integrated gene management. AMBIO: A Journal of the Human Environment 29(2):115-121.

Thrupp, L. A. 1998. Cultivating diversity. Agrobiodiversity and food security. Washington D.C: World Resources Institute.
2000. Linking agricultural biodiversity and food security: The valuable role of agrobiodiversity for sustainable agriculture. International Affairs 76(2):265-281.

Toledo, V. M., B. Ortiz-Espejel, L. Cortés, P. Moguel, and M. Ordońez. 2003.The multiple use of tropical forests by indigenous peoples in Mexico: A case of adaptive management. Conservation Ecology 7(3):9. http://www.consecol. org/vol7/iss $3 /$ art $9 /$.

Trinh, L. N., J. W. Watson, N. N. Hue, N. N. De, N. V. Minh, P. Chu, B. R. Sthapit, and P. B. Eyzaguirre. 2003. Agrobiodiversity conservation and development in Vietnamese home gardens. Agriculture, Ecosystems \& Environment. 97: 317-344.

Ugland, K. I., J. S. Gray, and K. E. Ellingsen. 2003. The species-accumulation curve and estimation of species richness. Journal of Animal Ecology 72(5):888-897.

Vandermeer, J., M. Noordwijk, J. Anderson, C. Ong, and I. Perfecto. 1998. Global change and multi-species agroecosystems: Concepts and issues. Agriculture, Ecosystems \& Environment 67(1):1-22.

Wale, E. 2011. Farmer's perceptions on replacement and loss of traditional crop varieties: Examples from Ethiopia and implications. In: The economics of managing crop diversity on-farm: Case studies from the genetic resources policy initiative, eds., E. Wale, A. G. Drucker, and K. K. Zander, 65-94. London and/or Washington, D.C.: Earthscan. 